\title{
Revisiting Erik Erikson's Legacy on Culture, Race, and Ethnicity
}

\author{
Moin Syed and Jillian Fish \\ University of Minnesota
}

Version Date: December 24, 2018

This article has been published as:

Syed, M., \& Fish, J. (2018). Revisiting Erik Erikson's legacy on culture, race, and ethnicity. Identity: An International Journal of Theory and Research, 18(4), 274-283.

10.1080/15283488.2018.1523729

Special Issue: Fifty years since "Identity: Youth and Crisis": A renewed look at Erikson's writings on identity

Contact moin@umn.edu or fishx174@umn.edu 


\begin{abstract}
In contemporary identity research Erik Erikson is seldom associated with work on culture, race, and ethnicity. What is ironic about this lack of association is that not only did Erikson consider these factors, but that they figured prominently into his theorizing. The purpose of this article is to provide an analysis of Erikson's views that is more accurate than is what is typically represented by: 1) reviewing a brief history of empirical research on identity development since Erikson, 2) providing a broad summary of Erikson's writing on how identity is shaped by culture, race, and ethnicity, 3) arguing that Erikson's work suggests that historical trauma serves as an ideological setting for the identity development of marginalized groups, and 4) describing how historical trauma is associated with threats to temporal identity integration, or selfcontinuity.
\end{abstract}

Keywords: Erikson, identity, culture, race, ethnicity, Native Americans, African Americans, historical trauma, identity integration, self-continuity 


\section{Revisiting Erik Erikson's Legacy on Culture, Race, and Ethnicity}

In contemporary identity research Erik Erikson is seldom associated with work on culture, race, and ethnicity. What is ironic about this lack of association is that not only did Erikson consider culture, race, and ethnicity, but that they actually figure prominently into his theorizing. Indeed, in recent years researchers have increasingly recognized this point and built it into their own theoretical and empirical work (Cooper, 2011; McLean \& Syed, 2015; Syed, 2012; Way \& Rogers, 2015). Nevertheless, this aspect of Erikson's work is either not widely known or not accurately portrayed (e.g., Bhatia, 2017), and to our knowledge there has been no formal, dedicated evaluation of this aspect of his work since it was published. The purpose of this article is to provide this much-needed analysis.

Our analysis is organized into four broad sections. In the first section, we provide a brief history of empirical research on identity development since Erikson with respect to the inclusion and exclusion of issues of culture, race, and ethnicity. This historical review is necessary to properly understand how Erikson has been portrayed in mainstream identity development research, and provides insights as to why his work is not typically associated with culture, race, and ethnicity. In the second section, we provide a broad summary of Erikson's writing on how identity is shaped by culture, race, and ethnicity, focusing on the general perspectives he incorporated in his work and how they are related to current perspectives in the field.

The first two sections of the paper can be thought of as introductory to the final two sections, which communicate the main thrust of this essay: a) that Erikson's work suggests that historical trauma serves as an ideological setting for the identity development of marginalized groups and b) how historical trauma is associated with threats to temporal identity integration and self-continuity. These two sections on historical trauma explicitly connect Erikson's writings to contemporary areas of research on identity development. That said, we do not focus much on contemporary research that has built directly upon Erikson's views on culture, race, and ethnicity, as our intention is to provide a concise and more accurate analysis of Erikson's views than is what is typically represented. Moreover, we hope this analysis will spur additional research on culture, race, and ethnicity from a contemporary Eriksonian perspective.

\section{Brief History and Background on Eriksonian Identity Research}

The contemporary empirical neo-Eriksonian tradition is commonly traced to Marcia (1966), who developed a protocol and a typology for assessing the "psychosocial criteria for determining degree of ego identity" (p. 551). This approach, which came to be known as the identity status model, was incredibly generative, establishing itself as the dominant approach to identity in developmental psychology. Marcia assessed three domains in his landmark study-occupational choice, religion, and political ideology. Fitting with the brevity that was characteristic of journal articles of that period, Marcia offered no justification for the inclusion of these three domains, although subsequently he and other identity scholars traced the decision back to Erikson's emphasis on work and ideology (which comprises both religion and politics; Arnett, 2015; Marcia, 1967; Schwartz, 2001). Additionally, the three domains were not examined separately but rather "global" identity statuses were calculated and interpreted. To be clear, there was no mention of race, ethnicity, or culture in this original work. 
The subsequent research continued in this vein through the 1960s and 1970s, examining such topics as the relation between identity statuses and situational self-esteem and anxiety (Marcia, 1967), identity statuses and intimacy (Orlofsky, Marcia, \& Lesser, 1973), and longitudinal changes in identity status classification (Waterman \& Waterman, 1971). Some studies during this era examined global identity status, and some examined occupation and ideology separately, but none made any mention of race, ethnicity, or culture.

The 1980s were a time when the identity status model was expanded to include additional domains and when serious evaluations and criticisms of the model began to emerge. In terms of expanded domains, Grotevant, Thorbecke, and Meyer (1982) extended the identity status interview, the method used at the time to assess the statuses, to include the interpersonal domains of friendship, dating, and sex roles, the rationale being that Erikson emphasized the importance of love in addition to occupation and ideology (see also Josselson, 1982). Grotevant et al. (1982) made passing reference to culture (i.e., Matteson's 1974 work in Denmark) but no mention of race or ethnicity. Two subsequent questionnaire-based measures of identity, the Extended Objective Measure of Ego Identity Status (EOM-EIS; Bennion \& Adams, 1986) and the Ego Identity Process Questionnaire (EIPQ; Balistreri, Busch-Rossnagel, \& Geisinger, 1995) further extended and formalized the status model as consisting of ideological (occupation, religion, politics, values) and interpersonal domains (friendships, family, sex roles, dating). Race and ethnicity were not discussed at all.

Evaluations and criticisms of the identity status model during that time focused largely on whether or not the identity status model reflected a developmental progression (Waterman, 1982), attempts to enhance the developmental focus of identity research (Grotevant, 1987), the degree to which the identity status model was an adequate reflection of Erikson's theory (Côté \& Levine, 1987; Waterman, 1988), and possible gender differences in identity process (Archer, 1989; Josselson, 1982). In none of these cases was the lack of attention to culture, race, or ethnicity a central critique of existing work. Grotevant (1987) briefly discussed the importance of "culture and society" for identity development, and noted that "Almost nothing is known about identity formation in non-White, non-middle class, non-college student populations within the United States" (p. 218). Côté and Levine (1987) made a relatively minor, passing reference to culture and society, mostly to the concept of "negative identity" among marginalized youth (see Hihara, Sugimura, \& Syed, 2018). These are important points of recognition, but there was little substance beyond what we reference here.

\section{Erikson, Marcia, and Ethnic Identity Development}

Although ethnic identity research has a long history in psychology, Jean Phinney is largely credited with motivating developmental research on the topic (see Umaña-Taylor et al., 2014). What distinguished Phinney's work from the previous research on ethnic identity was that she situated the study of ethnic identity within a pre-existing, widely used and accepted model: the identity status model. Phinney (1990) argued that ethnicity was likely to be particularly relevant for ethnic minority youth, and could thus be conceptualized as an identity "domain" just like the ideological and interpersonal domains that had been the focus of identity research.

One interesting aspect of this early research on ethnic identity is that Phinney demonstrated almost no engagement with Erikson's writings on culture, race, and ethnicity. One of Phinney's earliest and most widely cited articles began: 
In his seminal book on adolescent identity, Erickson [sic] (1968) devoted a chapter to the issue of race and ethnicity. He pointed out the likelihood that members of an "oppressed and exploited minority" ( $p$. 303) may internalize the negative views of the dominant society, thereby developing a negative identity and self-hatred. (1989, p. 34)

From there she moved directly to a discussion of social identity theory (Tajfel \& Turner, 1986) as relevant for understanding identity development among ethnic minority youth. In Phinney's (1990) now classic article that brought ethnic identity to the mainstream of developmental psychology, she expressly wrote that Erikson only "alluded" to culture in his theory, clearly indicating that it did not play a key role in his thinking. Subsequent articles contained either minimal or no reference to Erikson having any views on the matter (Phinney, 1992; Phinney \& Chavira, 1992). Rather, social identity theory continued to be the primary theoretical perspective provided to guide research on ethnic identity development.

To be clear, Phinney did not deny that Erikson considered culture, but rather after her earliest work simply made no claims about his work either way. This is also the case for the vast majority of subsequent ethnic identity research, wherein the intellectual linkage that brought ethnic identity research into developmental psychology is described as moving from Erikson to Marcia to Phinney (e.g., Yip, Seaton, \& Sellers, 2006). Although likely unintentional, the absence of explicit recognition of Erikson's work on this topic may have given the impression that Erikson and Marcia did not engage with it. Whereas this is true for Marcia and subsequent identity status researchers, it certainly is not for Erikson. Indeed, one of our primary goals for this paper is to make clear that such as impression is unequivocally false.

\section{Erikson on Culture, Race, and Ethnicity}

The preceding section detailed how identity researchers failed to incorporate, or even fully acknowledge, Erikson's work on culture, race, and ethnicity. In this section, we begin to remedy this misrepresentation by articulating some of the ways in which we did consider these issues in his theorizing. A challenge to this goal is that Erikson's writing is notorious for being expansive, complex, subject to divergent interpretations, and at times contradictory (see McAdams \& Zapata-Gietl, 2015; Peck, 2018; Waterman, 1988). In this section we attempt to focus on his broader perspective on issues of culture, race, and ethnicity; how he approached these issues, and how that approach relates to current research and theory in cultural and ethnic minority psychology. We then provide some examples of how that perspective was applied in his work. What should be clear from this overview is that Erikson brought a strong cultural perspective to his theorizing on identity development, a perspective that should be given full consideration when scholars engage with his work.

There are three features of Erikson's theorizing that are, somewhat surprisingly, consistent with current approaches in cultural and ethnic minority psychology. First, Erikson was fundamentally conducting comparative work, attempting to understand similarities and differences in cultural practices in development. Cauce, Coronado, and Watson (1998) discussed three predominant models of cultural comparison: cultural deviance, cultural equivalence, and cultural variance. In the cultural deviance model, Whites are seen as the standard from which all other ethnic groups are compared, an approach often referred to as the "deficit perspective." In contrast, the cultural equivalence model locates ethnic group differences within social structures 
and economic differences. This perspective is manifest in the "race is confounded with class" mantra, and has led to the practice of controlling for social class when making racial/ethnic comparisons (i.e., making them "equivalent"). Finally, the cultural variance model does not assume any one standard, or that different ethnic groups have the potential to be equal. Strong consideration for the minority context, which involves a life of institutional and personal oppression, renders any possibility of equal status impossible and that the differences can be sources of strength as well as sources of challenge. Given the epoch in which Erikson worked, it would not be unjustified to assume that he took a cultural deviance approach (Cabrera, 2013), and some have even explicitly indicated that is what he did (e.g., Bhatia, 2017). However, his work was firmly rooted in the cultural variance model, seeking to understand individuals' development within their own context, and not against a dominant ideal or under the assumption that equivalence can or should be achieved. In Identity: Youth and Crisis Erikson explicitly rebuked the "Moynihan Report" (pp. 301 \& 311), widely seen as a prototypical example of the deficit approach to understanding ethnic minority development.

Second, in conducting cultural comparative work, Erikson did not solely take a betweengroups approach, which tends to emphasize group differences in psychological processes (see Matsumoto et al., 2001). Rather, as we elaborate below, he paired between group comparisons (Native Americans and Whites) with within-group comparisons (Yurok and Sioux tribes) to account for nuances in the cultural nature of developmental processes.

Finally, and perhaps most notably, Erikson took a strong structural perspective throughout all of his writing, examining how social, historical, and political contexts within a racialized society interact with individual development. This type of perspective has been noticeably lacking in psychology in general (Syed, Santos, Yoo, \& Juang, in press) and in the psychological study of identity in particular (Hammack, 2008; McLean \& Syed, 2015). For Erikson, the structural was deeply intertwined with the individual.

In describing Erikson's views we primarily draw upon two chapters in Childhood and Society ("Hunters Across the Prairie" and "Fisherman Along a Salmon River") and one chapter from Identity: Youth and Crisis (Race and the Wider Identity). We chose to take this approach because these are the writings that most explicitly engaged with issues of culture, race, and ethnicity. To be sure, such discussions are present in Erikson's other writings, but by drawing upon these specific chapters we can best communicate the broad stroke of Erikson's views on these issues. In the following paragraphs we provide more detail on his work on Native American (Sioux and Yurok) and African American development.

In Childhood and Society, Erikson's consideration of culture centers on the Sioux and the Yurok. Before describing his work, we first acknowledge that Sioux is not the preferred term of the Lakota and Dakota, but we adhere to this terminology as it is unclear what tribes Erikson was referring to in addition to the Oglala Lakota from the Pine Ridge Reservation. Though Erikson used the term Dakota at times in his writings, it remains uncertain which Dakota tribes he was referring to - if any at all. Erikson explicitly mentioned visiting the Pine Ridge Reservation, which primarily comprises the Oglala Lakota. Other than the Pine Ridge Reservation, Erikson mentioned visiting a nearby reservation of a closely related tribe, and though he could have been referring to Dakota tribes, we cannot say for certain given the multiple tribes in the surrounding area. In terms of limitations to understanding Erikson's work, this is of note as we do not have a complete and clear picture of the population his theorizing referenced, nor can we say how 
Erikson's writings correspond with what we know of particular tribes today, though we can speak about it in more general terms.

In cross-cultural fashion, Erikson approached his work with the Sioux and Yurok comparatively, documenting his experiences with the tribes separately and offering a subsequent analysis of their variations and similarities. Despite their different life contexts, Erikson drew some parallels between the Sioux and Yurok, describing both tribes as primitive, ethnocentric, and concerned with tribal self-determination. His work across tribes emphasized development in context, stressing the ways in which individual identities are a function of the broader societal structures that individuals are embedded within. Early on in his writings about the Sioux and Yurok, Erikson posited social and behavioral norms as culture-dependent, noting that "primitives have their own adult normality ... brands of neurosis and psychosis and . . their own varieties of childhood" (1963, p. 111).

Despite referring to the Sioux and Yurok as primitives - a common misconception advanced by anthropologists - Erikson was well aware of cultural norms and how norms differed between cultures, stating that Native American peoples had their own set of standards for what constitutes developmental milestones, and even mental illness. Not only did Erikson contrast the child rearing practices of Whites and the Sioux, but he also explicitly referenced within-group differences between the Sioux and Yurok, noting variations in personality, spirituality, development, and culture, and how these variations were associated with their relative ability to develop healthy identities.

Those who read the chapters dedicated to the Sioux and Yurok will find that Erikson provided a much more thorough examination of the Sioux than he does the Yurok. One of the reasons for this is that the Sioux seemed to pose a more interesting population for him given his interest in sociocultural threats to identity development. As we describe in more detail below, the Sioux had experienced greater disruptions to their immediate context relative to the Yurok, which have direct implications for their identities. Nevertheless, what Erikson recognized in both groups is how centuries of colonialism and war can pervade the developmental context of identity. The central challenge for Native American identities was finding a way to reconcile traditional ways of life with the new realities in front of them, all within a context that refused to support this critical identity work. These insights informed a broader abstraction of identity being fundamentally concerned with establishing a sense of continuity across time and context, and how societal institutions can both facilitate and constrain the development of continuity.

In Identity: Youth and Crisis, Erikson recognized the quest for identity as the core of the "Negro Revolution," by which he meant the slow process of "emancipation from the remnants of colonial patterns of thoughts" (p. 295). Like his use of the label "Sioux" discussed previously, his use of "Negro" was partly a product of his time, and partly a product of uncritical examination of externally-imposed group labels. Erikson's discussion of race and identity was almost exclusively structural. For example, he focused extensively on the legacy of colonialism and slavery, and how they had constrained African American identity options. This context ascribed to African Americans either the lack of an identity or a negative identity, which is an identity based on opposition to mainstream social forces (see Hihara et al., 2018). Accordingly, the collective identity work of African Americans is to assert their personhood, agency, and value. This collective identity work is critical for well-being but made all the more challenging by the dominant white majority's ongoing motivation to maintain power and superiority (see pp. 
298-299). This point is important, because it situates colonialism and slavery not just as factors in the past that have residual influence, but rather ongoing oppressive forces that shape opportunities for positive development. This perspective stands in strong contradiction to a "post-racial" view that has been promulgated since the civil rights era (Bonilla-Silva, 2015).

The idea that temporal and historical factors can be separable, even if important, aspects of human development can be clearly seen in Bronfenbrenner's (1979) popular ecological theory, in which the chronosystem was not part of the original model and, pictorially, sits on the outskirts of the model. Recently we re-conceptualized Bronfenbrenner's model for Native American development, placing the chronosystem at the center of the model (Fish \& Syed, 2018). The significance of this move is that it indicates that no other system in the model (e.g., microsystem, macrosystem) can be considered independent of temporal and historical factors. In other words, the historical context is the most fundamental aspect of Native American identities, infusing all other influences and experiences. Based on Erikson's work, a similar argument could be made for African American identities (and likely many other groups).

Like his writings about the Sioux and Yurok, Erikson was attempting to understand African American identities within their context, and not in relation to some other, external standard. But he did so in somewhat different ways. Whereas with the Sioux and Yurok he focused on identity development within the strivings and challenges to maintain a traditional culture in a changing society, for African-American identities he focused on the struggle to create positive identities within a society that had long-denied the opportunity to develop them. Although these are clearly different contexts for development, they share an emphasis on historical factors for understanding current identity development, and in particular the role of historical traumas for understanding identity development of marginalized groups.

\section{Historical Trauma as an Ideological Setting for Marginalized Groups}

What Erikson's writings lack in specificity, and at times clarity, are countered by his keen attention to the big picture impacts of historical and cultural factors. Erikson offered a thorough structural analysis in his work with the Sioux and Yurok, one that attended to their historical experiences and how they helped shape their development. Embedded throughout his theorizing, Erikson underscored experiences of historical trauma and its subsequent impact.

Although the psychological implications of the intergenerational transmission of trauma have long been investigated (see Fromm, 2012), the current theoretical and empirical literature on historical trauma stems from Maria Yellow Horse Brave Heart's (1998) pioneering research with the Lakota. According to Brave Heart, historical trauma refers to the "cumulative emotional and psychological wounding across generations, including the lifespan, which emanates from massive group trauma" (Brave Heart, Chase, Elkins, and Altschul, 2011, p. 283). The available theoretical work on historical trauma has informed other related concepts, such as the historical trauma response (Whitbeck, Adams, Hoyt, \& Chen, 2004) which refers to reactions to largescale collective trauma, and includes unresolved grief, emotional distress, as well as symptoms characteristic of PTSD (Brave Heart, et al., 2011; Evans-Campbell, 2008). In addition to impacting individuals, historical trauma has been demonstrated to take a toll on families and communities through child rearing practices and the destruction of social structures (e.g., tribal sovereignty), respectively (Evans-Campbell, 2008). Importantly, the current literature 
acknowledges that responses to historical trauma are likely to differ due to variations in historically traumatic events, as well as regional and cultural factors.

Throughout his theorizing, Erikson touched on most of (if not all) of these topics. Well before concepts of historical trauma were introduced to the psychological literature, Erikson related these phenomena to difficulties with attachment, parenting, and emotional expression, which can be seen in the subsection of Childhood and Society entitled, "An Interracial Seminar." While gathering information concerning child development, Erikson pointed to variations in how outsiders characterized Native American parents and their children, including that Native American parents did not love or express affection towards their children, and the inverse, that Native American peoples were fond of their families (Erikson, 1963, pp. 125-126). Erikson had difficulty reconciling such differences in opinion, but did note that cultural disintegration coupled with not being able to provide for children economically and spiritually could indeed impact interpersonal relationships. Erikson discussed the impact of colonization, including warfare, loss of land, the death of the buffalo, and boarding schools on attachment and emotional expression among the Sioux - which is consistent with the theoretical and empirical literature concerning historical trauma. Describing these events as "an apocalyptic sequence of catastrophes" (Erikson, 1963, p. 116) is suggestive of Erikson's awareness of how such events structured the experiences of individuals within a given culture across generations. Erikson even highlighted differences in colonial experiences and acculturation between the Sioux and Yurok, and consequently, varying degrees of impact on their psychological wellbeing. Additionally, Erikson described differences in the colonial histories of the Sioux and Yurok, which is notable given that researchers unfamiliar with the diverse composition of Native American tribes have a tendency to overlook such variations.

Indeed, Erikson clearly considered historical trauma to play an integral role in the development of the Sioux and Yurok. Although there is little direct discussion of historical trauma phenomena in his writing on African Americans identities, he does attend to the impact of history and context, albeit, in different terms than historical trauma. His discussion of "current day" African American identities, characterized by negative identities, denial of personhood, and so on, were rooted in the "historical trauma" of colonialism, slavery, and their subsequent sociocultural manifestations. Rather than a sense of "loss" with the Sioux and Yurok, Erikson discussed a sense of "never was" for African American identities, thus motivating the need to assert cultural representation.

Structural oppression was a central aspect of Erikson's theorizing in general, but with African American identities he delved much deeper on the topic than with the Sioux and Yurok, elaborating not only on structural oppression but also internalized oppression. Internalized oppression is the process by which oppressed groups come to internalize and adopt the negative views and stereotypes transmitted by the oppressive majority (David, 2014). Although it has its roots in theorizing by Franz Fanon (1965), empirical psychological research on internalized oppression is relatively recent. Erikson provided a clear, albeit circumscribed, discussion of how being systematically undermined informs identity development and the implications of forming an identity that is based on the negative stereotypes and beliefs imposed by dominant society. We will elaborate and contextualize this point in the subsequent section.

In sum, for all forms of marginalization that Erikson discussed, a concept akin to historical trauma serves as the ideological setting for identity development. Ideological settings 
are the broader societal-level beliefs and values that underlie a normative life in a given context, and thus signify the collective psychological context within a particular context (Hammack, 2008; Syed et al., in press). The psychological phenomena that Erikson theorized on are situated within the context of historical trauma, suggesting the fundamental necessity of considering historical trauma to understand the development of groups facing longstanding trauma in general, and Native Americans in particular (see Fish \& Syed, 2018). We next briefly illustrate how a historical trauma perspective relates to temporal integration and self-continuity, which was a broad topic of interest to Erikson and subsequent identity development researches.

\section{Threats to Temporal Integration and Self-Continuity}

Temporal integration, or the synthesis of individual's past, present, and future selves, is a core indicator of positive psychosocial functioning in Erikson's theory of identity development (see Syed \& McLean, 2016). Similarly, Chandler (1994) and others have used self-continuity to refer to the personal and collective ability to form a self-conception that extends backwards into the past and forward into the future. Forming a coherent sense of self hinges on this very ability to connect the persons we have been to the persons we are becoming. This task, which can be difficult when a given cultural group has been oppressed, serves as the foundation to a coherent sense of self (Chandler \& Lalonde, 1995). Developing a coherent sense of self can be especially challenging for Native American peoples in light of the marginalization of tribal culture and the damage it has inflicted upon their cultural continuity.

When writing about the Sioux and Yurok, Erikson discussed how the ever-shifting historical and social context can make connecting the past to the future a difficult task, and thus serves as a major barrier to constructing a healthy identity. Erikson argued that this is especially difficult for the Sioux who had experienced several changes in different life roles and their general lifestyle as a result of the changing historical and social context. The strong contrast in these domains impedes individuals' abilities to construct a sense of self that coherently links the past to the future. This phenomena is clearly delineated in the summary of his work with the Sioux, when Erikson states:

The Sioux, under traumatic conditions, has lost the reality for which the last historical form of his communal integrity was fitted. Before the white man came, he was a fighting nomad and a buffalo hunter. The buffalo disappeared, slaughtered by invaders. The Sioux then became a warrior on the defense, and was defeated. He almost cheerfully learned to round up cattle instead of encircling the buffalo: his cattle were taken from him. He should become a sedentary farmer, only at the price of being a sick man, on bad land (1963, pp. 153-154).

It is through this sequential process that the Sioux were refused access to the foundation required to form a collective identity. In taking into consideration the role that self-continuity plays in the experiences of the Yurok, it is important to note some differences between the two tribes that Erikson was attuned to. As mentioned previously, Erikson considered the Yurok to adhere to centrifugal planes of existence, meaning that the Yurok lived in an isolated location that is not easily accessed by outsiders (along a forested coast, nested alongside mountains and valleys). Similar to most visitors, Erikson noted that he is not readily welcomed by the Yurok into their village, however, when he was, he was quick to point out that the Yurok had strong ancestral and land connections as a result of this localization, stating: 
An old Yurok asked me to drive him to his ancestors' home. When we arrived, he proudly pointed to a hardly noticeable pit in the ground and said "This is where I come from." Such pits retain the family name forever. In fact, Yurok localities exist by name only in so far as human history or mythology has dignified them. These myths do not mention mountain peaks or the gigantic redwoods which impress white travelers so much; yet the Yurok will point to certain insignificant-looking rocks and trees as being the "origin" of the most far-reaching events (Erikson, 1963, p. 167).

Erikson's reflections suggest that the Yurok experienced a relative sense of continuity in comparison to the Sioux that hinged on the preservation of significant cultural anchors including ancestral ties, connections to the land, and origin stories (cf. Chandler \& Lalonde, 1995). The secluded location of the village limited visitors and disruptions in cultural continuity, thus, nourishing a sense of self at the local level of the Yurok. Despite this, it is important to note there were (are) still threats to self-continuity at the broader, sociocultural level. Erikson recognized this, discussing oppression at great lengths, and how prolonged and unjust, systematic treatment affects one's sense of identity.

As noted, rather than a "loss of identity," Erikson described African Americans as being historically denied one altogether. Although he wrote about this as an absence of identity or as a negative identity, he actually indicated a preference for the term surrendered identity. This concept is meant to index that there is a historical existence and culture that serves as the foundational past for African American identities, but through the slave trade that identity was "surrendered" to the White oppressors, who have held control of it ever since. This is an attractive concept because it situates threats to self-continuity within structural relations rather than dispositional characteristics of African Americans. Moreover, surrendered identity indicates that there is an identity there to be reclaimed, and that there is hope for establishing the sense of self-continuity that is so vital to healthy identity development.

\section{Conclusion and An Invitation}

The purpose of this article was to take a renewed look at Erikson's writings on how identity is shaped by culture, race, and ethnicity. Our general conclusion is that Erikson not only considered such factors, he did so deeply and in a way that is quite consistent with contemporary theory and research in cultural and ethnic minority psychology. This suggest that, just as his work has sparked new interests and ideas in other areas of identity research (e.g., Schachter, 2004), Erikson's work should be seen as a useful resource for scholars interested in structural perspective on identity development (e.g., McLean \& Syed, 2015). Indeed, this paper is by no means the final word on this subject. We invite interested readers to take a look for themselves, and read the three chapters that we reference in detail, if not the entire books. Erikson's writing is a rich and engaging collection of ideas that can inspire new theoretical developments and empirical studies. But the reading should not be done casually, and a failure to engage fully with the readings could lead to misunderstandings of apparent intent (e.g., Bhatia, 2017).

Nevertheless, we feel that those who choose to engage will be deeply rewarded with thoughtful and insightful ideas about how we find our way in a cultural world. 


\section{References}

Archer, S. L. (1989). Gender differences in identity development: Issues of process, domain and timing. Journal of Adolescence, 12(2), 117-138.

Arnett, J. J. (2015). Identity development from adolescence to emerging adulthood: What we know and (especially) don't know. In K. C. McLean \& M. Syed (Eds.), The Oxford handbook of identity development. New York: Oxford University Press.

Balistreri, E., Busch-Rossnagel, N. A., \& Geisinger, K. F. (1995). Development and preliminary validation of the Ego Identity Process Questionnaire. Journal of adolescence, 18(2), 179192.

Bennion, L. D., \& Adams, G. R. (1986). A revision of the extended version of the Objective Measure of Ego Identity Status: An identity instrument for use with late adolescents. Journal of Adolescent Research, 1(2), 183-197.

Bhatia, S. (2017). Decolonizing psychology: Globalization, social justice, and Indian youth identities (Chapter 4). New York: Oxford University Press.

Bonilla-Silva, E. (2015). The structure of racism in color-blind, "post-racial" America. American Behavioral Scientist, 59(11), 1358-1376.

Brave Heart, M.Y.H. (1998). The return to the sacred path: Healing the historical trauma response among the Lakota. Smith College Studies in Social Work, 68, 287-305.

Brave Heart, M.Y.H., Chase, J., Elkins, J., \& Altschul, D. B. (2011). Historical trauma among indigenous peoples of the Americas: Concepts, research, and clinical considerations. Journal of Psychoactive Drugs, 43, 282-290.

Cauce, A.M., Coronado, N., \& Watson, J. (1998). Conceptual, methodological, and statistical issues in culturally competent research. In M. Hernandez \& R. Mareasa (Eds.), Promoting cultural competence in children's mental health services. Baltimore: Paul Brooks Publishing.

Cabrera, N. J. (2013). Positive Development of Minority Children. Social Policy Report, 27(2).

Chandler, M. (1994). Adolescent Suicide and the Loss of Personal Continuity. In D. Cicchetti \& S. L. Toth (Eds), Disorders and dysfunctions of the self (pp. 371-390). Rochester, NY: University of Rochester Press.

Chandler, M. J., \& Lalonde, C. E. (1995). The problem of self-continuity in the context of rapid personal and cultural change. In A. Oosterwegel, \& R. A. Wicklund (Eds.), The self in European and North American culture: Development and processes (pp. 45-63). Berlin, Germany: Springer Science+Business Media.

Cooper, C. R. (2011). Bridging multiple worlds: Cultures, identities, and pathways to college. Oxford University Press.

Cote, J. E., \& Levine, C. (1987). A formulation of Erikson's theory of ego identity formation. Developmental review, 7(4), 273-325.

David, E. J. R., \& Derthick, A. O. (2014). What is internalized oppression, and so what? In E. J. R. David (ed), Internalized oppression: The psychology of marginalized groups. New York: Springer.

Evans-Campbell, T. (2008). Historical trauma in American Indian/Alaska Native communities: A multilevel framework for exploring impacts on individuals, families, and communities. Journal of Interpersonal Violence, 23, 316-338.

Erikson, E. (1963). Childhood and society. New York, NY: W. W. Norton \& Company.

Erikson, E. (1968). Identity: Youth and crisis. New York, NY: W. W. Norton \& Company. 
Fanon, F. (1965). The wretched of the earth. New York: Grove.

Fish, J., \& Syed, M. (2018). Native Americans in higher education: An ecological systems perspective. Journal of College Student Development, 59(4), 387-403.

Fromm, G. M. (Ed.). (2012). Lost in transmission: Studies of trauma across generations. London: Karnac Books.

Grotevant, H. D. (1987). Toward a process model of identity formation. Journal of adolescent research, 2(3), 203-222.

Grotevant, H. D., Thorbecke, W., \& Meyer, M. L. (1982). An extension of Marcia's identity status interview into the interpersonal domain. Journal of youth and adolescence, 11(1), 33-47.

Hammack, P. L. (2008). Narrative and the cultural psychology of identity. Personality and Social Psychology Review, 12(3), 222-247.

Hihara, S., Sugimura, K. \& Syed, M. (2018). Forming a negative identity in contemporary society: Shedding light on the most problematic identity resolution. Manuscript submitted for publication.

Josselson, R. (1982). Personality structure and identity status in women as viewed through early memories. Journal of Youth and Adolescence, 11(4), 293-299.

Marcia, J. E. (1966). Development and validation of ego-identity status. Journal of personality and social psychology, 3(5), 551.

Marcia, J. E. (1967). Ego identity status: relationship to change in self Lesteem, "general maladjustment," and authoritarianism. Journal of personality, 35(1), 118-133.

Matsumoto, D., Grissom, R. J., \& Dinnel, D. L. (2001). Do between-culture differences really mean that people are different? A look at some measures of cultural effect size. Journal of Cross-Cultural Psychology, 32(4), 478-490.

Matteson, D. R. (1977). Exploration and commitment: Sex differences and methodological problems in the use of identity status categories. Journal of Youth and Adolescence, 6(4), 353-374.

McLean, K. C., \& Syed, M. (2015). Personal, master, and alternative narratives: An integrative framework for understanding identity development in context. Human Development, 58, 318-349.

McAdams, D. P., \& Zapata-Gietl, C.(2015). Three strands of identity developmeht across the human life source: Reading Erik Erikson in full. In K. C. McLean \& M. Syed (Eds.), The Oxford handbook of identity development. New York: Oxford University Press.

Orlofsky, J. L., Marcia, J. E., \& Lesser, I. M. (1973). Ego identity status and the intimacy versus isolation crisis of young adulthood. Journal of personality and social psychology, 27(2), 211-219.

Peck, S. C. (2018). Revisiting Erikson's Neglected Concepts of Ego-Identity and Self-Identity: Hidden Persuaders in the Twilight Zones of Awareness. Archives of Psychology, 2(1).

Phinney, J. S. (1989). Stages of ethnic identity development in minority group adolescents. The Journal of Early Adolescence, 9(1-2), 34-49.

Phinney, J. S. (1990). Ethnic identity in adolescents and adults: review of research. Psychological bulletin, 108(3), 499-514.

Phinney, J. S. (1992). The multigroup ethnic identity measure: A new scale for use with diverse groups. Journal of adolescent research, 7(2), 156-176. 
Phinney, J. S., \& Chavira, V. (1992). Ethnic identity and self-esteem: An exploratory longitudinal study. Journal of adolescence, 15(3), 271-281.

Schachter, E. P. (2004). Identity configurations: A new perspective on identity formation in contemporary society. Journal of personality, 72(1), 167-200.

Schwartz, S. J. (2001). The evolution of Eriksonian and, neo-Eriksonian identity theory and research: A review and integration. Identity: an international journal of theory and research, 1(1), 7-58.

Syed, M. (2012). The past, present, and future of Eriksonian identity research: Introduction to the Special Issue. Identity: An International Journal of Theory and Research, 12(1), 1-7.

Syed, M., \& McLean, K. C. (2016). Understanding identity integration: Theoretical, methodological, and applied issues. Journal of Adolescence, 47, 109-118.

Syed, M., Santos, C., Yoo, H. C. B., \& Juang, L. P. (in press). Invisibility of racial/ethnic minorities in developmental science: Implications for research and institutional practices. American Psychologist. https://psyarxiv.com/hg9fm/

Tajfel, H., \& Turner, J. C. (1986). The social identity theory of intergroup behavior. In S. Worchel \& WG Austin (Eds.), Psychology of intergroup relations: 7-24. Chicago: Nelson-Hall.

Umaña-Taylor, A. J., Quintana, S. M., Lee, R. M., Cross, W. E., Rivas-Drake, D., Schwartz, S. J., Syed, M., Yip, T., Seaton, E., \& Ethnic/Racial Identity Study Group. (2014). Ethnic and racial identity revisited: An integrated conceptualization. Child Development, 85(1), 21-39.

Waterman, A. S. (1982). Identity Development From Adolescence to Adulthood: An Extension of Theory and a Review of Research. Developmental Psychology, 18(3), 341-358.

Waterman, A. S. (1988). Identity status theory and Erikson's theory: Communalities and differences. Developmental Review, 8(2), 185-208.

Waterman, A. S., \& Waterman, C. K. (1971). A longitudinal study of changes in ego identity status during the freshman year at college. Developmental Psychology, 5(1), 167-173.

Whitbeck, L., Adams, G., Hoyt, D., \& Chen, X. (2004). Conceptualizing and measuring historical trauma among American Indian people. American Journal of Community Psychology, 33, 119-130.

Way, N., \& Rogers, O. (2015). “[T] hey say Black men won't make it, but I know I'm gonna make it": Ethnic and racial identity development in the context of cultural stereotypes. In K. C. McLean \& M. Syed (Eds.), The Oxford handbook of identity development. New York: Oxford University Press.

Yip, T., Seaton, E. K., \& Sellers, R. M. (2006). African American racial identity across the lifespan: Identity status, identity content, and depressive symptoms. Child Development, 77(5), 1504-1517. 